\title{
A TALE OF TWO SISTERS: AGE, AGENCY AND TRADITION AMONG THE YUGAN KHANTY
}

\author{
Andrew Wiget, Olga Balalaeva
}

\begin{abstract}
Categorical oppositions such as Tradition and Modernity are often employed to explain conventional behavior, because there is a presumed consonance between the goals of the agent and the values of the context in which the agent acts, but such categorical oppositions do not seem to effectively model acts of choosing. An individual Khant experiences a sense of participating in several social identities, each providing a context for forming intentions to act, mobilizing resources, seeking legitimation, and following through on commitments to act. Among the Khanty the sense of belonging to an age cohort differs from other biologically-marked categories such as clan, patriliny, even gender, by having no particular prescriptions associated with it. It is a 'modern' phenomenon in two senses of the word: first, historically, it seems to have been brought into being through a modern institution, the boarding school; second, it is 'modern' in the sense that it is perceived as an empowering category, liberating one from the constraints of tradition. This paper, based on the authors' fifteen-year-long association with two Khanty sisters, raised in a taiga settlement, explores the values implicit in choices they make as they begin to define for themselves a path towards an adult identity.
\end{abstract}

Key words: age cohort, agency, identity, Khanty, modernity, tradition, values, youth

Our fieldwork among the Yugan Khanty has left many memorable images. For example, after coming to the very top of the Malyi Yugan River about 350 kilometers by boat from the village administration and the nearest infrastructure, to Kaimysov extended family settlement or yurta, we entered to find a poster featuring the stars of the now infamous American television soap opera, "Santa Barbara". Our hosts, two young brothers, had just recently purchased a television, which they powered from an electric generator they had received as part of an oil company agreement, and they were caught up in the serial. We also remember coming out of Kurlomkin's yurta, about 500 kilometers up the Bolshoi Yugan River, to greet a party of guests from a neighboring yurta who were on their way downriver to the village. A young girl in the group struck us, being dressed in absolutely traditional Khanty fashion, except for a pair of bright red high-heeled shoes. To some degree, this article has been 
provoked by a range of such choices made by indigenous youth, from listening to and performing pop music and dressing in punk clothes to, sadly, sniffing glue and committing suicide. The article will reflect on how these choices are made, and then talks about two young Khanty women.

\section{AGENCY AND STRUCTURE, TRADITION AND MODERNITY}

Theories of agency as different as philosophical action theory (Davidson \& Suppes 1977, Davidson 1980), sociological Rational Choice Theory (Elster 1986, 1989), and Bourdieu's (1977) habitus and practice, despite represent action as intentional, springing from an individual goal orientation. Because the individual considers that undertaking such an action will advance him or her towards a goal that will satisfy his or her needs, such actions are personally valuable, and such an action is personally meaningful if it is rationalized within the individual's understanding of the world in which the action takes place. In so far as the goals towards which the action is directed are shared by a social group to which the individual belongs, the action is socially valuable, and the action is culturally meaningful if it is rationalized within the group's understanding of the world in which it takes place. Action requires not only intention but commitment, a willingness to enact intentions.

In theoretical formulations, Agency is often opposed to Structure, in the sense that all actions take place within a socially structured context, so that the meaningfulness of alternative goals, strategies and instrumentalities is always already there, though to a degree which remains to be specified. However, the fact that the socially-structured context can never be fully specified means that although socially sanctioned alternatives are presented, their meaning and value never overdetermine choice. Moreover, if one considers that the agent is herself a socially-sanctioned signifier capable of assigning meaning and value to elements of the context, even to the point of rationalizing and proposing an 'unconventional' alternative, then the Agency-Structure opposition collapses into the liminal, fluid phenomenon, which Giddens (1984) calls 'structuration'. All other categorical oppositions, such as Self-Society, SocietyWorld and Tradition-Modernity, are also understood not to exist a priori but to result from acts of structuration.

Categorical oppositions - and here we include Tradition and Modernity are often employed to explain conventional behavior, because there is a presumed consonance between the goals of the agent and the values of the context in which the agent acts, though it must be said even here categorical oppositions do not very well, because they do not seem to effectively model 
acts of choosing (compare Sewell 1992). Explanations of unconventional choices are more difficult, however, and tend to follow one of two tracks. Either such choices are attributed to personal idiosyncrasy, and therefore some psychological explanation is sought, or they are attributed to a change in the context of choice, as having introduced new, "unexpected" alternatives. Conventional ethnography eschews psychological explanations in favor of contextual ones, and many of the changes we observed in our own work, including weakening exogamy, changes in ritual behavior, loss of folk medicine traditions, changes in diet and so on, we might attribute to "external" factors such as the introduction of the market economy, compulsory education, the arrival of missionaries, access to mass media, and the like. Yet neither the psychological nor the contextual explanatory strategy is satisfactory in itself, because even a contextually "novel" alternative must be rationalized by the agent as valuable and meaningful, in short, personally appropriated, in order to be the object of intentional action. Moreover, because the agent's own socially constructed context of action is almost certainly more fluid and porous than ethnography's reconstruction of that context, the sense of novelty observers may notice may be created by the way their own explanations construct a sense of the context of choice.

Nowhere has the historical and social contingency of explanation proved more true in the social sciences than in the discussion of "tradition" and "traditional cultures", concepts that emerged to stabilize the shift to social modernity. When phenomenon of societal modernity (Gaonkar 1999) emerged in the West at the end of the eighteenth century, it was characterized by the rise of industrial capitalism, the spread of republican democracy, the development of a broad public sphere of political and cultural activity, and the emergence of a rhetoric of personal liberty and individualism. Simultaneously, a "colonial modernity" emerged as inextricably linked to societal modernity (Mignolo 2000) precisely because the characteristics of social modernity just described were based on imperialist economies that depended upon colonial markets and colonial natural and human resources. One result of the emergence of these two modernities in Western nation states has been a confounding of individual and communal identities, which cannot be easily regulated by immigration, naturalization and other identity-based laws, nor easily neutralized or erased by claims to legal equality. Russia is no exception to this confusion, especially in regards to "northern peoples" and "traditional cultures" (Slezkine 1996).

The concept of "traditional culture" resulted from the perception of historical differences between emergent modern societies and those societies that they displaced into an "other" category, which came to be called "traditional". Classical anthropology reified "traditional cultures" by creating the holistic, 
objectified, systematized representation of other societies, which are now so widely criticized. The category of "traditional" was also objectified as an inventory of immutable, normative forms that are passively inherited from prior generations. Such a conception is easily deconstructed, of course, and shown to be instead a sense of the past that is actively created in the present, to paraphrase Handler and Linnekin (1984), by a panoply of agents (indigenous, scientific, governmental, popular public, journalistic, and so on) for a variety of different purposes. Nevertheless, in Russia as we know, this misconception still holds popular sway, even among indigenous people. ${ }^{1}$

That the "traditional" is a category defined by, and in relation to, modernity, is a matter of consequence in any discussion of identity and agency. First, in the modern, secular citizen-state, especially in the liberal democracies, citizenship is presumed to marginalize all other distinctions, such as religion, ethnicity, language, gender, race, and kinship, rendering them irrelevant (or at least unnecessary) for the essential functions of society, yet these are in fact the very categories of social identification often considered to be the most significant in societies denoted as traditional, where knowledge and agency are often both legitimated and circumscribed in just these terms. Second, modern societies historically have been erected upon industrial capitalist economies that promoted an ideology of general access to natural and human resources, open competition, and the spur of economic self-interest. Thus modern societies also differ from traditional societies by placing a heightened emphasis on individual autonomy in order to facilitate the unrestrained circulation of commodities in order to maximize the opportunity for individuals to accrue wealth. Third, in modern, industrial societies the mechanical reproduction of cultural forms led to the commodification of cultural forms and information (Benjamin [1936] 1968). By commodifying culture and information, and radically associating the production and consumption of culture and information with the individual, modernity asserted the portability of both culture and information, as so well symbolized by the paperback book, the cassette tape, and the computer diskette. This modern perception contrasts sharply with the notion, central to traditional cultures, that knowledge and cultural production is bound to a specific community living in a specific time and place.

These heuristic characterizations of modernity and tradition are useful for enabling us to think about agency in ways that enable comparison. Thus, on the one hand, we may argue that modernity is characterized by an abstraction of identity (reducing the social to the functional), an emphasis on individual autonomy, and commodification. As debilitating as such modernity may appear in our post-Romantic age, the result can in fact be just the opposite, as exemplified by Michel Callon's study of the strawberry market in Sologne, France, which 
paradoxically $[\ldots]$ strengthened the agency of buyers and sellers (to act as 'economic men') by cutting social relations rather than creating them. The components of the market constituted an empowerment network. By creating 'space' for the freer, or less inhibited interactions of intentions and commitments, they played a constitutive role for the performance of a particular kind of action. (Bruun \& Langlais 2003)

On the other hand, traditional social identities and the networks they entail are often considered empowering for precisely the opposite reason: the density of social relations provides a multiplicity of resources, from whom the individual can solicit material assistance as well as legitimation for her actions, as evidenced by numerous studies on task-group formation and the emerging understanding of kinship fictions. Recent ethnography has paid a good deal of attention to the role of the territorial citizen-state in providing an array of possibilities for "belonging", for negotiating and transgressing categorical boundaries towards shaping new nationalist identities, especially in the context of 'interethnic' relations, that authorize a sense of 'entitlement' (Fondahl 1996, Schindler 1997, Anderson 2000, Anderson 2002, Wilson 2002). However, the current understanding of kinship as a symbolic reality (Nuttall 1992, Schweitzer 2000) suggests that throughout the North other symbolic categorical relationships may also offer meaningful fields for claims of "belonging".

An individual Khant experiences a sense of participating in several social identities, each providing a context for forming intentions to act, mobilizing resources, seeking legitimation, and following through on commitments to act. These include but are not limited to:

Gender

Patriliny (extended family)

Spouse's Patriliny (for women)

Clan (Khanty, sir)

Age Cohort (defined mostly but not entirely through the agency of the Internat $\left.{ }^{2}\right)$

River-System Residence Group (yakh)

Family-Kinship Territorial Group (semeino-rodovye obshchina)

Native Community Association (nacional'naia obshchina)

Dialectical (Eastern Khanty)

Ethnos (Khanty)

Political Minority (malochislennye korennye narody severa)

Rossianin (member of Russian society) 
Some of these contexts, like gender, patriliny, clan and perhaps local residence group, are "traditional" in the historical sense that they predate the imposition of Russian power. These contexts structure choice through constraints of custom. Others are historically "modern" in the sense that they result from the imposition of state power, and structure choice through legal constraints; these include Family-Kinship Territorial Group, Native Community Association, ethnos in the political sense, political minority and rossianin in the sense of citizenship. Age cohort represents a special case, the discussion of which will be postponed for the moment.

However much these contexts constrain choice, it would be wrong to think of these "contexts" as shaped entirely by others. To reiterate a point made earlier, these contexts and the alternatives they offer must be rationalized by the agent as personally valuable and meaningful in order to be the object of intentional action. This is true even for the Khanty person living in an extended family settlement in the bush, operating in the sphere that Bourdieu termed habitus, who moves apparently effortlessly and seamlessly through the morning, for example, doing any or all of the following: sewing beadwork, making a basket, telling a riddle, giving instruction, setting and baiting a trap, smoking fish, or singing a song while repairing a sled. For such an individual these actions no longer require the conscious rationalization of alternatives, any more than the actions of driving a car do for many urban Westerners. They once did, however, and only because of their habituation do they now constitute the horizon of the conventional or the "traditional".

\section{TWO SISTERS}

Darya and Tatiana are the two daughters of Mikhail V and his second wife. Darya, the older, was born in 1979, and Tatiana in 1984 (in this section we have changed the names to protect individual identities). Although Darya has since married and moved out, when we first met them - Olga in 1988 and myself in 1992 - they all lived together in the family yurta. They live deep in the taiga, at least two days by boat from the major village in the region, where the extended family supports itself almost entirely by subsistence hunting and fishing and the trapping of furbearers to sell for cash. They have no electricity, telephone, gas or other permanent infrastructure, and live in a house entirely of their making. Their father, Mikhail, had only four years of schooling; their mother, Nadezhda, none. The father is a renowned storyteller and singer and in his younger days used to lead Bear Festival rituals. We provide these facts as a kind of preliminary certification of the family's "traditionality" in the popular sense of the word. 
Although only thirteen in 1992, Darya was very much the older sister. Indeed, she was already a young woman, and we watched, impressed, as she carried out her tasks, from sewing to making baskets to cooking and baking bread, demonstrating all the capabilities of a young housewife. Over the next couple of years, we watched her setting nets, smoking fish, and checking snares, and we marveled at her memory, her ability to listen to her father tell a Khanty tale over an hour long in Khanty, and then provide an almost word-for-word Russian translation. At the same time, one of the first gifts that Darya requested from us was a cassette player. She was beginning to collect cassette tapes of singers she had first heard with other children at the Internat, which she left after only six years. Darya grew up quickly, and, given her readiness and attractiveness, we thought it would not be long before she would marry. She was about fourteen then, when we asked her if she planned to marry a Khanty hunter and live on stoibishe. "No," she said, "I want to marry a Ukrainian and live in Ugut." Why, we asked naively, a Ukrainian? "Because they are rich," she said. Probably her role models for this aspiration were two Khanty women, each of whom married the Ukrainian storekeepers in the small villages of Ryskiny and Taurova, but there were also several Ukrainians working with oil companies in Ugut. Ugut is a large village with the population of 1,200 , the administrative center of the village district covering the Yugan, with a hospital, school, stores, Internat and regular transport connections to Surgut, the biggest city in Khanty-Mansi Autonomous Okrug. Though we did not know it then, fourteen-year-old Darya had also developed a romantic attachment to a Belarusian oil worker, and had gone so far to visit the oil workers' camp several times. He made gifts to her, they exchanged cassettes, and in a short time the relationship became something of a scandal.

Young Khanty women are expected to be publicly modest, and though some might have had sexual experiences as teenagers while away at boarding school, and while such experiences might affirm adolescent egos, these experiences are not approved of and never discussed publicly. Darya's persistence in behavior which she must have known to be both scandalous and fruitless - being a migrant worker, he returned home, leaving her in the forest, as she must have known he would - might be attributable to many causes, including a distressing family life. It seems clear now, in hindsight, that young Darya had begun weaving notions of wealth, romantic love and a powerful, attractive non-Khanty man into tapestry of fantasies about marrying out of the taiga. And while she had some role models of Khanty women marrying non-Khanty men, the power of her fantasy, as measured by its ability to drive her selfconsciously into scandalous behavior, is out of all proportion to the real-life situations of these few Khanty women. Instead the power of that fantasy must 
be rooted elsewhere, and we would suggest that the most likely source is the sexually-charged fantasy of romantic love which has become part of every young Khanty's experience through their encounter with popular culture in villages and in boarding schools in post-Soviet Russia. In the first boarding school generation, who went to school in the late 1930s and during the war years, and which included the girls' father, men average 2.5 years of schooling, women 1.5 years; in the girls' generation, men averaged 7.5 years of schooling, and the girls 6.5 years. Darya's father, born in 1936 and schooled during and after the Second War, probably had limited access even to radio, and saw a Soviet film at the local House of Culture perhaps only two or three times a year when he came to the village for supplies. By contrast, while at school, Darya's imagination was nourished during her preadolescent and adolescent years by popular music, television, and film; some of these were accessible on portable media - radio and cassette tape - to which she had continued access while at home on yurta in the forest.

At age sixteen she had married a young hunter and moved to his household on Malyi Yugan. Not only was her choice something of a surprise, but also the manner in which she enacted it. According to others, after a family quarrel she ran away from home to Ugut, where she found the young man, proposed common law marriage, and left Ugut directly to take up residence at his yurta without giving her family any explanation. Her family accepted the fact of her elopement with resignation. Even today young Khanty understand that there are values and customary practices associated with choosing a spouse. In a spouse, Khanty value hard work, loyalty, family commitment and intergenerational respect. The latter is especially important as Khanty households often included a pensioner-grandparent, and while marriages are no longer strictly arranged, the custom of making gifts to the parents of the prospective bride and soliciting their permission through intermediaries still exists. In the context of persisting traditions, Darya's elopement was markedly unconventional, and even something of an affront. According to Darya, she had first become acquainted with this young man at the boarding school, though he was several years older than her, and for several years prior to the elopement she had had her eye on him. She acknowledged that she had had a quarrel with her family, but she did not think that her elopement was anything extraordinary. Again we would argue that such an evaluation could only be acceptable to a romantic imagination fueled by mass culture and motivated to self-aggrandizing fantasies by a sense that her home life had become intolerably oppressive. One might say there is nothing unusual in this story, that one could find a thousand such stories, explained in just this way, in any city in the world, but this is precisely the point. 
Although at first Darya's young man had some difficulty adjusting to suddenly finding himself with a wife, and his visits to former female friends provoked Darya's jealousy, as of today, they have been married for five years, and things have "settled down." He is a good father and hunter, Darya a good Khanty wife, and they still live together with their two children. Indeed, visiting them at their yurta, one would be hard-pressed to imagine that such a "traditional" family emerged from a series of "untraditional" choices. One might suggest that her youthful fantasies, fostered by her exposure to popular culture, never coalesced into a clear intention, let alone a commitment to act, despite their attraction and power. It also seems clear that her leaving the forest in a romantic adventure was a fantastic displacement of a more easily realized intention, which was simply to leave a distressing home situation, one which she could not control, and establish another social environment which she could control.

Darya's sister Tatiana is now eighteen. We last saw her two weeks ago (August 2004) in Khanty-Mansiysk where she had accompanied her father to an international conference where he was presented an award. Her father was awed and delighted to be in the regional capital - at age 68 it was his first time - but Tatiana was nonplussed. At eighteen, this was her second trip. When Olga first met Tatiana, she was four, her age in this family photograph, which shows her in a pedal car toy, indicating that, although she lived $500 \mathrm{~km}$ by boat from the nearest infrastructure, from the beginning Tatiana, like her sister, grew up in a social and material context that engaged Russian popular culture. In her teen years, Tatiana developed a history of illness that has taken her from school for stays in the hospital lasting as long as a month or two. Tatiana now has completed eleven years of school, the last two through the evening school program because of health reasons, and she has her diploma. During those school sessions, as well as her visits to Surgut (she has also been there more times than her father), Tatiana was fully exposed to the range of Russian popular culture disseminated through films, television and recorded music. She also had a romantic involvement with an older, acculturated Khanty man living in Ugut, where she spent a lot of time either in school or in the hospital. Like her sister, Tatiana has been prepared entirely for the role of a Khanty wife and mother. Watching her grow up as we did, our expectation was that her future was as a Khanty wife managing a taiga household. Tatiana is skilled in home-craft, and since Darya has moved away, she has spent much of the time taking care of her aging parents' household, because her mother's failing eyesight prevents her from doing so. Unlike her sister at that age, however, Tatiana has a very clear career goal in mind. She wants to be a paramedic working among the families living along the Bolshoi Yugan near her family 
yurta. Tatiana's first trip to Khanty-Mansiysk was last year when she had taken some paramedic training.

Within the horizon of her present expectations, Tatiana has made a conscious choice to stay on the Yugan. Only marriage, at this point, would seem to provide sufficient motivation for her to move away. At an age when most Khanty girls are already married or thinking about marriage, Tatiana confesses no present romantic involvements or plans to marry. Nor do any of the local Khanty young men along the Yugan seem to look upon her with interest, perhaps because of the story of her relationship in Ugut but equally as likely is that she has fallen out of favor because she has lost touch with her age cohort by missing so much school. She also has developed a certain prideful air, communicating to everyone her intention to become a doctor. It is unlikely that she will pursue a higher education with a view towards becoming a nurse or doctor, career moves that would definitely take her out of the taiga and commit her to a different life trajectory than her sister's. On the other hand, her need for additional training may provide the occasion for developing a relationship that would lead to marriage, and that eventuality would certainly remove her from her father's yurta and perhaps from the taiga entirely.

I wish to close by returning to the postponed subject of age cohort as a context for agency. Khanty of all generations have a very clear sense of their age cohort, even though nothing in Khanty culture distinguished age groups functionally: there are no initiations, distinctive costumes, or prescribed practices associated with age. In former times there was a sense of the stariki, the elders, and this still persists, though the term today refers more to age than to deference. Apart from this one category, there seems be no clear reference to a sense of age cohorts in the past. However, at least since the $1930 \mathrm{~s}$, the principal factor in dramatically heightening the sense of an age cohort, the development of an age-peer sense, has been compulsory in boarding school education. Even the oldest generation now can identify those with whom they went to school. Setting aside for a moment the exposure to mass culture in the boarding school environment, and considering only age cohort by itself as a context for action, it is also clear that different age cohorts subscribe to different sets of values. This is not unexpected, even in "traditional" societies (Grindal 1973). Among Khanty, however, age differs from other biologically-marked categories such as clan, patriliny, even gender, by having no particular prescriptions associated with it. It is the identity category least constrained by custom. To this must be added the fact that the boarding school environment is a constitutive one, providing the resources for imagining and the occasion for enacting non-traditional choices. We would go so far to say that among the Khanty the sense of belonging to an age cohort is a 'modern' phenomenon in 
two senses of the word: first, historically, it seems to have been brought into being through a modern institution, the boarding school; second, it is 'modern' in the sense that it is perceived as an empowering category, liberating one from the constraints of tradition.

It is common to point to boarding schools as agents provocateurs, enabling unconventional behavior in traditional societies and hastening acculturation. This case is most often made statistically and based on a number of assumptions. In this paper we have tried to provide a theoretical framework for understanding why, among the Khanty, boarding schools may provoke a context for unconventional behavior in individual students from traditional households. However, we hasten to add, this is no guarantee that in any individual case the long-term consequences of participating in the boarding school environment will lead to dramatic forms of acculturation. This suggests that agency theory, which so often focuses on how an individual articulates the reasons for a choice at hand, would profit from developing some temporal perspective on individual lives to better understand the nature and directionality of individual choices, because today's choice may or may not become tomorrow's custom.

\section{NOTES}

1 As an aside, may we remark that it seems particularly disingenuous for members of dominant society to be scandalized that indigenous people have learned to benefit politically from the deployment of the term "traditional", when in fact the majorities in modern nation states, who created the category of the "traditional" have deployed it to their own political and economic advantage for nearly three centuries.

${ }^{2}$ Boarding school.

3 The site where nomads set up their tents (chums).

\section{REFERENCES}

Anderson, David G. 2000. Identity and Ecology in Arctic Siberia: The Number One Reindeer Brigade. Oxford: Oxford University Press.

Anderson, David G. 2002. Entitlements, Identity and Time: Addressing Aboriginal Rights and Nature Protection in Siberia's Resource Colonies. In: E. Kasten (ed.) People and Land: Pathways to Reform in Post-Soviet Siberia. Berlin: Dietrich Reimer Verlag, pp. 99-123.

Benjamin, Walter [1936] 1968. The Work of Art in the Age of Mechanical Reproduction. Illuminations. English transl. by Harry Zohn. New York: Harcourt Brace Jovanovich. 
Bourdieu, Pierre 1977. Outline of the Theory of Practice. Transl. by Richard Nice. Cambridge: Cambridge University Press.

Bruun, Henrik \& Langlais, Richard 2003. On the Embodied Nature of Action. Acta Sociologica Vol. 46, No. 1, pp. 31-49.

Davidson, Donald 1980. Essays on Actions and Events. Oxford: Oxford University Press.

Davidson, Donald \& Suppes, Patrick 1977. Decision-Making: An Experimental Approach. Chicago: University of Chicago Press.

Elster, Jon (ed.) 1986. Rational Choice. Oxford: Basil Blackwell.

Elster, Jon 1989. The Cement of Society: A Survey of Social Order. Cambridge: Cambridge University Press.

Fondahl, Gail 1996. Contested Terrain: Changing Boundaries and Identities in Southeastern Siberia. Post-Soviet Geography and Economics Vol. 37, No. 1, pp. 3-15.

Gaonkar, Dilip Parameshwar 1999. On Alternative Modernities. Public Culture. Vol. 11, No.1, pp. 1-18.

Giddens, Anthony 1984. The Constitution of Society: Outline of the Theory of Structuration. Berkeley: University of California Press.

Grindal, Bruce. 1973. The Sisala Trickster Tale. Journal of American Folklore. Vol. 86, pp. 173-174.

Handler, Richard \& Linnekin, Jocelyn 1984. Tradition, Genuine or Spurious? Journal of American Folklore. Vol. 97, pp. 273-290.

Mignolo, Walter D. 2000. Local Histories / Global Designs: Coloniality, Subaltern Knowledge and Border Thinking. Princeton: Princeton University Press.

Nuttall, Mark 1992. Arctic Homeland: Kinship, Community and Development in Northwest Greenland (Anthropological Horizons, Vol. 2). Toronto: University of Toronto Press.

Schindler, Debra 1997. Redefining Tradition and Renegotiating Ethnicity in Native Russia. Arctic Anthropology. Vol. 34, No. 1, pp. 194-211.

Schweitzer, Peter P. (ed.) 2000. Dividends of Kinship: Meanings and Uses of Social Relatedness. London: Routledge.

Sewell, William H. Jr. 1992. A Theory of Structure: Duality, Agency, and Transformation. The American Journal of Sociology. Vol. 98, No. 1, pp. 1-29.

Slezkine, Yuri 1994. Arctic Mirrors: Russia and The Small Peoples of the North. Ithaca: Cornell University Press.

Wilson, Emma 2002. Est' zakon, est' i svoi zakony: Legal and Moral Entitlements to the Fish resources of Nyski Bay, North-Eastern Sakhalin. In: E. Kasten (ed.) People and Land: Pathways to Reform in Post-Soviet Siberia. Berlin: Dietrich Reimer Verlag. pp. 149-168. 